\title{
Information Use by Molecular Biologists: Implications for Library Collections and Services
}

\author{
Julie M. Hurd, Deborah D. Blecic, and Rama \\ Vishwanatham
}

This article reports on findings from a citation analysis of publications of a group of university molecular biology faculty. The study examined the formats and disciplines of materials cited in published articles to determine the nature of information used in their research. Citations in molecular biologists' publications are overwhelmingly to journal articles, with the largest number of citations to journals that class in biology. The specialization displays a very high level of immediacy with a citation half-life of referenced articles just over four years. Ranked lists of journals cited provide insights to support library decision-making. The authors explore implications for library information services, collection development and management, and the potential for electronic services to this population. This research provided data on a local user population and also identified a methodology that may be utilized in other settings.

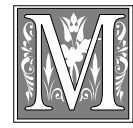

olecular biology is an active scientific research specialization that seeks to understand the nature of biological phenomena at the molecular level by studying the roles of various molecules in living cells. Molecular biology first emerged as a specialization in the 1940s as biochemists, geneticists, and biophysicists came together to study the three-dimensional structures of proteins. Their early research led to a fuller understanding of the structure of deoxyribonucleic acid (DNA), the basic building block of all living material. Initially, the methodologies available to molecular biologists restricted their stud- ies to simple living systems, those of bacteria and viruses. By the 1970s, the development of recombinant-DNA technology using enzymes to cut and recombine segments of DNA in chromosomes permitted the study of a broader array of plant and animal cells.

Recombinant-DNA technology applied to plants and animals led to the development of genetic engineering and practical applications of what had previously been a pure science. Molecular biology research now sees applications in science, medicine, agriculture, and industry in such developments as "designer drugs" engineered to treat specific dis-

Julie M. Hurd is Associate Professor and Science Librarian at the University of Illinois at Chicago; e-mail: jhurd@uic.edu. Deborah D. Blecic is Assistant Professor and Bibliographer for the Life and Health Sciences at the University of Illinois at Chicago; e-mail: dblecic@uic.edu. Rama Vishwanatham is Assistant Professor and Assistant Reference Librarian in the Library of the Health Sciences at the University of Illinois at Chicago; e-mail: rama@uic.edu. 
eases or in new forms of fruits or vegetables developed to resist disease or with enhanced storage life. Popular press attention has focused on molecular biology in stories of the polymerase chain reaction that figured significantly in a 1997 high-profile murder trial and for which chemist Kary Mullis received a Nobel prize, and of the success of a Scottish research team that cloned the sheep Dolly from the cells of another adult sheep. Molecular biology research now finds application in the treatment of life-threatening conditions and in the enhancement of agricultural production. It promises improved quality of life for many and is an important area of study at almost every research university with programmatic strength in the life sciences.

\section{Background}

In 1995, the University of Illinois at Chicago (UIC) celebrated the opening of a newly constructed research facility, the Molecular Biology Research Building (MBRB). This state-of-the-art laboratory was planned and built to meet the needs of faculty and their graduate students who were engaged in research that classed broadly as "molecular biology." Faculty working in this specialization are affiliated with several departments and had previously been dispersed among a number of sites on campus; some lacked convenient access to appropriate technology because their laboratories were in older buildings with dated infrastructures. Centralizing the university's molecular biology research would support more efficient use of expensive shared diagnostic and analytical equipment. Bringing this community of scientists to a single attractive and well-equipped building also might promote new collaborations and strengthen existing relationships.

If the MBRB had been built thirty years ago, it very likely would have included a branch library containing the books and journals most needed to support molecular biology research. That many of these might have duplicated materials held by the relatively close Library of the Health Sciences (LHS) and/or the more distant Science Library would have been less an issue in the more generously funded era of the 1960s. But in the 1990s, this was not a viable scenario. In fact, both the LHS and the Science Library had, through years of careful attention to use studies and circulation data, already canceled many of their duplicate serial subscriptions. At the same time, the University Library wished to provide services that would meet the information needs of this group of scientists. The authors of this article are all directly involved in provision of library services in the basic and health sciences and undertook this study to gain a better understanding of the needs of this particular user population.

\section{Related Research}

Interdisciplinary and rapidly developing specializations such as molecular biology present particular challenges to research libraries. Core lists of journals and important reference sources may not exist to guide collection development. New techniques and emerging vocabularies pose problems of subject access. Library budgets may need to support acquisitions of new specialty journals, and public services librarians may be called upon to assist in locating information scattered across disciplines. Molecular biologists could be expected to use library resources in biochemistry, genetics, and biophysics, reflecting the roots of the field, as well as materials that would class in molecular biology itself. In addition, electronic resources are growing in importance for this field with the proliferation of genetic sequencing information stored in shared databanks such as European Molecular Biology Laboratory (EMBL) and GenBank.

Bibliometrics, including citation analysis, provides a methodology for identifying materials used by a particular population, where use is measured by citations in publications of the individuals who comprise the group. Bibliometric techniques are well suited to studies of disci- 
plines where publication is primarily journal based and, consequently, have seen numerous applications in investigations of scientific literatures. An analysis of references cited by authors provides information on formats, disciplines, ages, and countries of publication of materials that were utilized in preparing the source publication. The Institute for Scientific Information's (ISI) citation indexes available in print and electronic formats have provided raw data for numerous citation analyses that have enriched our knowledge of the materials that are important for library collections.

Katherine W. McCain has employed bibliometrics to study the literature of various scientific specializations and has often interpreted her findings within a context of serials management. She uses co-citation analysis to identify networks of journals with substantial intercitations and is able to map the subject structure of fields and demonstrate links to literatures of other specializations. For example, McCain examined the literature of genetics and concluded that "genetics lacks a single unified core literature" but, rather, consists of loosely linked research specialties, each with its own "core" journal set. ${ }^{1}$ She discussed the implications for collection managers of her findings and suggested that the ISI databases, coupled with standard statistical and spreadsheet software, are tools that make this analytical approach available to many librarians.

In addition, McCain has used bibliometric methodologies to explore interdisciplinarity in emerging specialties and to study journal use by a local population. McCain and James E. Bobick employed citation analysis of faculty publications, doctoral dissertations, and preliminary doctoral qualifying briefs to assess journal use by the biology department at Temple University. ${ }^{2}$ Their findings supported collection maintenance and development decisions, and were one of the first published studies of a "local citation analysis."

Rosalind Walcott obtained "local knowledge" concerning the users of the biology library at the State University of New York at Stony Brook by studying the citation patterns in the theses and dissertations of graduate students. ${ }^{3}$ The impetus for her investigation was an impending serials cut. She intended to complement a use study of faculty by gathering information on graduate students, the largest and most active group of library users. Walcott collected data on format, language, and age of cited materials, and identified a ranked list of most-cited journals. She examined differences among the specializations offered by the Division of Biological Sciences: Molecular Biology and Biochemistry, Genetics, Cellular and Developmental Biology, Ecology and Evolution, and Neurobiology and Behavior. The details of her analysis were used in a serials cancellation project and to inform other collection development and management decisions.

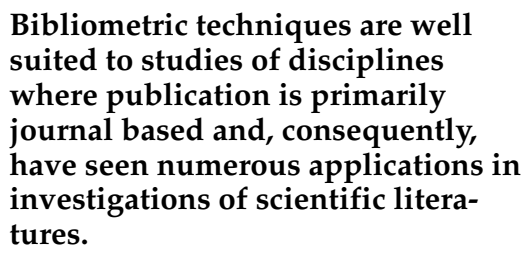

Bibliometric techniques are well suited to studies of disciplines where publication is primarily journal based and, consequently, have seen numerous applications in investigations of scientific literatures.

Janet Hughes utilized publication information for faculty at the Pennsylvania State University, coupled with ISI Journal Citation Report data, to create a ranked list of titles in molecular and cellular biology in order to support a serials evaluation project. ${ }^{4}$ Her analysis identified interdisciplinary citation patterns and a list of high-use titles different from those in discipline-wide rankings that likely reflect local research strengths. Her study validated the significance of several general science journals, including Proceedings of the National Academy of Sciences (U.S.), Science, and Nature, for molecular and cellular biologists at Penn State.

McCain, Walcott, and Hughes all have employed bibliometric analyses to examine aspects of the detailed structure of the biological sciences literature. These stud- 
ies affirm that the scientific journal is the most important component of formal communication among biologists. Where these researchers have focused on local populations, whether faculty or graduate students, they have used publication-related data and statistical approaches to identify core collections of journals for use in supporting library decisions. Although the details of their approaches varied, certain generalizations can be drawn from their research, including:

\section{A total of sixty articles was identi- fied representing an average output of three articles per publishing faculty member for the period under study.}

- Molecular biology research draws on a multidisciplinary knowledge base that reflects its own origins as well as the diversity of applications of research in the specialization.

- Molecular biology research is high profile and is published in the most prestigious general science journals as well as in the specialty publications of the field and other corollary fields.

- Subspecializations and institutional research agendas account for variations in use patterns among subgroups that diverge from discipline-wide norms.

The authors undertook a citation analysis based on the recent journal publications of the faculty whose research labs were in the MBRB. Such a local citation study would provide an unobtrusive measure of materials that these scientists acknowledged as important by referencing them in their publications. The findings of the citation analysis could then be augmented by complementary information gathered from circulation data, in-house use studies, and faculty surveys to better characterize a set of information resources for molecular biology research.

\section{Methodology}

The interdisciplinary nature of the campus molecular biology cohort was reflected in the departmental affiliations of the faculty moving to the new lab. The two largest groups of scientists on campus engaged in molecular biology research were members of either the Laboratory of Molecular Biology based in the biological sciences department of the College of Liberal Arts and Sciences or the Department of Genetics in the College of Medicine. A smaller group of faculty was affiliated with other departments, mostly in the College of Medicine. The authors obtained lists from each department of faculty who would be based in the new facility and combined them to define the survey population. Thus, the research reported in this paper represents a snapshot of this group of scientists as they were relocating their laboratories; the potential for a long-term study documenting any changes in their use of information is addressed later in this article.

The total roster of faculty who would be assigned to the new laboratory included twenty- four faculty from five different departments holding the rank of professor, associate professor, or assistant professor. Faculty with clinical track appointments, or designated as visiting or emeritus faculty, were excluded from the study because expectations for research and scholarly publication likely differ for these groups.

The investigators searched all sections of the Current Contents database to produce a list of recent article publications of the MBRB faculty. When no publications were found for a particular individual in Current Contents, other discipline-specific databases were searched to identify research published in journals not indexed by the Institute for Scientific Information. Twenty of the twenty-four faculty comprising the population had published at least one article during the previous three years. A total of sixty articles was identified representing an average output of three articles per publishing faculty member for the period under study. The range for this group of authors was from one to nine articles.

A stratified sample was drawn from the entire population of sixty articles. For 


\begin{tabular}{|ll|}
\hline \multicolumn{2}{|c|}{ TABLE 1} \\
\multicolumn{2}{|c|}{ Journals in Sample Population } \\
(N = 44 articles)
\end{tabular}

and institutional affiliations. The number of institutions listed ranged from one to nine per paper, with an average of 1.9. Coauthors were affiliated with not only other universities, but also with hospitals, research institutes, or pharmaceutical and biotechnology corporations. Not all authors indicated a departmental affiliation; some were associated with organizations that may not have been organized into departments. For articles providing departmental identification on authors, the range in the sample was from one through five, with an average of 1.6 departments listed per paper. The research articles in this sample show that molecular biology research is carried out by teams whose members may collaborate across institutional, political, and disciplinary boundaries. Molecular biology is an

each author, up to three articles were included, using all of an author's publications if there were three or fewer. For those authors who had published more than three articles, three were selected at random from the total output. The sample included only research articles; review articles were excluded if encountered. The sample drawn for the citation analysis comprised forty-four articles.

The typical article in the sample analyzed was coauthored by 4.4 scientists and cited 38.3 references. The number of coauthors varied from two to fifteen; there were no single-authored papers in the sample. Each article's header provided information on the authors' departmental interdisciplinary specialization rather than one based in a single type of organization or identified with a particular department.

\section{Findings}

The forty-four articles in the sample were published in twenty-seven different journals whose titles are listed in table 1 . The subject category to which each journal is assigned in Ulrich's International Periodicals Directory, 33rd edition, appears in the table as does the number of articles in the sample published in that journal. This group of molecular biologists publishes in journals that class in biology, medicine, and science. The category "science" is 


\begin{tabular}{|lrr|}
\hline \multicolumn{3}{|c|}{ TABLE 2 } \\
Formats of Cited References \\
(N = 1,683 references, & $\mathbf{4 4}$ articles $)$ \\
\hline \hline & \# of citations & \% \\
\hline Format & 1,537 & 91.3 \\
Journals & 68 & 4.0 \\
Monographs & 42 & 2.5 \\
Reference Materials & 8 & 0.5 \\
Theses & 20 & 1.2 \\
Unpublished & 7 & 0.4 \\
Conference Proceedings & 1 & 0.1 \\
Other &
\end{tabular}

used by Ulrich's for multidisciplinary publications that cover more than one scientific discipline. The largest number of articles (seven) appear in the very prestigious multidisciplinary journal Proceedings of the National Academy of Science (U.S.).

The references in each paper in the sample were analyzed by first classifying each cited item by format of publication: journal article, monograph, conference proceedings, reference work (i.e., table, handbook, data compilation, etc.), dissertation or thesis, or unpublished source. The designation "conference proceedings" was reserved for compilations of papers presented at symposia or conferences that were not published as a regular issue of a journal. The category includes proceedings appearing as special supplements to journals, irregularly published monographic series, or edited collections not in a series. The designation "unpublished" was used for those citations to materials cited as "in preparation," "in press," or "unpublished data," as well as to those identified as "personal communication." Table 2 summarizes the analysis of formats of cited references.

Among the reference materials cited, two titles stood out in the frequency with which they appeared. Sixteen papers cited either or both the multivolume serial set Methods in Enzymology, published by Academic Press, and Molecular Cloning: $A$ Laboratory Manual, published by the Cold Spring Harbor Laboratory Press. These appear to be standard sources for methodologies used frequently by molecular biologists.

None of the forty-four articles in the sample of faculty publications cited any electronic source, whether an electronic journal or database. However, four of the forty-four articles did acknowledge that genetic sequences determined in the research reported had been deposited in a computer repository accessible to interested readers. Three authors indicated that they had deposited sequence data in GenBank or the EMBL database, and one author had data available on a personal FTP site.

McCain conducted an exploratory study of journal policies and procedures regarding "research-related information" including nucleotide and protein sequence data, X-ray crystallography data, and information on unique biological materials. ${ }^{5}$ She examined published journal policies and instructions to authors and determined that many journals dealing

\begin{tabular}{|lccc|}
\hline \multicolumn{4}{|c|}{ TABLE 3 } \\
\multicolumn{4}{|c|}{$\begin{array}{c}\text { Subject Classes of Cited Journal References } \\
\text { (N = 1,537 references, 44 articles) }\end{array}$} \\
\hline \hline \multicolumn{4}{c}{ Citations by } \\
Ulrich's & Biological & Citations by & All \\
Subject Classes & Sciences & Genetics & Faculty \\
of Cited Journals & Faculty* & Faculty* & Citations \\
\hline Biology & $81.9 \%$ & $54.6 \%$ & $59.4 \%$ \\
Chemistry & 0.9 & 0.3 & 0.5 \\
Medicine & 0.9 & 18.2 & 17.7 \\
Pharmacy & 0.0 & 0.4 & 0.7 \\
Physics & 0.2 & 0.0 & 0.1 \\
Public Health & 0.0 & 0.0 & 0.1 \\
Science & 13.9 & 22.8 & 18.2 \\
Unclassified & 2.2 & 3.6 & 3.5 \\
Total citations & 447 & 939 & 1,537 \\
\hline * These differences satisfy a chi-square test of statistical \\
significance, $p<0.05$
\end{tabular}




\begin{tabular}{|lcc|}
\hline \multicolumn{3}{|c|}{ TABLE 4 } \\
Most-cited Journals \\
\multicolumn{3}{|c|}{ (N = 1,537 total citations to 267 journals) } \\
\hline \hline Journal & \# of Citations & Ulrich's Class \\
\hline Proceedings of the National & 154 & Science \\
$\quad$ Academy of Science (U.S.) & & \\
Cell & 89 & Biology \\
Molecular and Cellular Biology & 83 & Biology \\
Journal of Biological Chemistry & 75 & Biology \\
Nucleic Acids Research & 66 & Biology \\
Nature & 64 & Science \\
Science & 59 & Science \\
Journal of Bacteriology & 54 & Biology \\
EMBO Journal & 39 & Biology \\
Gene & 29 & Biology \\
Journal of Molecular Biology & 27 & Biology \\
Brain Research & 26 & Medicine \\
Journal of Neurophysiology & 23 & Biology \\
Journal of Physiology (London) & 22 & Biology \\
Genetics & 20 & Biology \\
Plant Physiology & 20 & Biology \\
\hline
\end{tabular}

editorial policies; the authors expect that references to gene databanks will be found increasingly in their publications.

In this sample of molecular biologists' publications, articles in refereed scientific journals made up the most frequently cited format; 91.3 percent of the cited references were to journal articles. This heavy reliance on journals is consistent with findings reported by others. For example, Robin B. Devin compiled a listing of the percentages of serial citations in various subject literatures; microbiology authors cite 93.1 percent serials. ${ }^{7}$ Walcott deter-

with sequence data require that nucleic acid sequences be deposited in a database such as GenBank or EMBL prior to publication. Ann C. Weller described the growth of these databases and provided a perspective on the critical role of journal editors in transforming genetic information to an electronic medium. ${ }^{6}$ When journal editors require use of depositories for genetic sequence data, they contribute to the building of a critical mass of such data in a centralized electronic store and encourage others using these data to expect an electronic source. Leading journals such as Journal of Biological Chemistry, Nucleic Acids Research, and Proceedings of the National Academy of Science (U.S.) now provide instructions to authors on submission of sequencing data; an accession number provided by the database is evidence of receipt by the depository. Availability of sequencing data in one of the depositories enhances the reviewing process and, ultimately, provides readers of published articles with fuller access to research results. Molecular biologists who determine gene sequences will likely participate in these emerging depositories because of journal mined that molecular biology and biochemistry graduate students cited 95.1 percent serials in their dissertations. ${ }^{8}$

Each journal citation in the sample articles was assigned to an Ulrich's subject category in the same manner as were the source journals in which the citing article appeared. Table 3 summarizes the distribution among subject classes of 1,537 journal articles cited by this group of molecular biologists. Table 3 also presents data on the distribution among subject classes for the two largest subsets of molecular biologists, those from the departments of genetics and biological sciences.

Biology journals represent the largest subject category of journals cited by the entire population; 59.4 percent (913 citations) of the citations were to journals that class in biology. General science is the next largest category of cited journals at 18.2 percent (279 citations), followed closely by medicine at 17.7 percent ( 272 citations). The authors of this study questioned whether citation patterns might differ based on the departmental and college affiliation of molecular biologists and separated data from respondents in genetics and biological sciences to explore 
the issue. Data presented in table 3 show that faculty affiliated with either department cite journals in biology most frequently, but those affiliated with the Department of Genetics in the College of Medicine account for almost all the citations to medical journals. These data satisfy a chi-square test for statistical significance of the differences between the two departments.

\section{The citation age for each journal article referenced was calculated by subtracting the year of publication of the cited article from the year of publication of the citing article.}

Table 4 is a ranked list of the journals cited most often by the entire group of responding molecular biologists. Although 267 different journals were cited in the publications analyzed, the sixteen titles listed in table 4 account for 55.3 percent of the citations. The three general science journals, Proceedings of the National Academy of Science (U.S.), Nature, and Science, alone account for 18 percent of the cited references. This relatively small group of journals, most of which class in biology or general science, provides a significant portion of resources supporting molecular biology research on campus. Not all of these titles would necessarily come to mind if one were asked to identify the "most important" journals in molecular biology. Hughes's list includes ten of these titles among her top twenty journals, but several of the titles frequently cited by UIC researchers do not appear at all in the Penn State ranking. ${ }^{9}$ Walcott's ranking of journals in molecular biology and biochemistry includes nine of these titles among her top twenty journals. ${ }^{10}$ Variations among the populations very likely reflect, in part, research specializations on the three campuses. Such variations, even among highly cited titles, argue for the value of "local citation analyses" to support institutional decisions.

Molecular biology is a specialization with a very active research front; such fields often rely most on very recent literature. To explore that issue, the citation ages of cited journal articles were computed. The citation age for each journal article referenced was calculated by subtracting the year of publication of the cited article from the year of publication of the citing article. Figure 1 provides a picture of the age distribution of molecular biology citations and is typical of obsolescence curves for other scientific fields such as physics and chemistry. Fifty-eight percent of the material cited was five years old or less at time of publication of the citing article. These findings compare to Walcott's determination that 50 percent of the molecular biology and biochemistry citations in her study were to articles five years old or less. ${ }^{11}$ The hypothesis was confirmed; molecular biology is a field with a high degree of immediacy where the most current journals are likely to be the most heavily used.

\section{Implications for Information Services}

This analysis of the publications of molecular biologists reveals a traditional, paper-based use of primary information sources heavily dependent on the scientific journal. When these scientists visit a library, they will likely be looking for journal articles published within the past five years or for Methods in Enzymology. A long-term, questionnaire-based study of UIC faculty by Karen L. Curtis, Julie M. Hurd, and Ann C. Weller provides evidence that scientists use both paper and electronic secondary services to identify journal articles of interest and that they rely on the library to provide access, either locally or through interlibrary loan, to journal articles not in their personal collections. ${ }^{12}$ Questionnaires administered in 1991 and 1995 have documented that faculty are in the midst of a transition from print to electronic versions of secondary services such as MEDLINE/Index Medicus, Current Contents, and others. Faculty are also increasingly connected to local computer networks and the Internet from offices, laboratories, and homes, and are using computer-mediated com- 


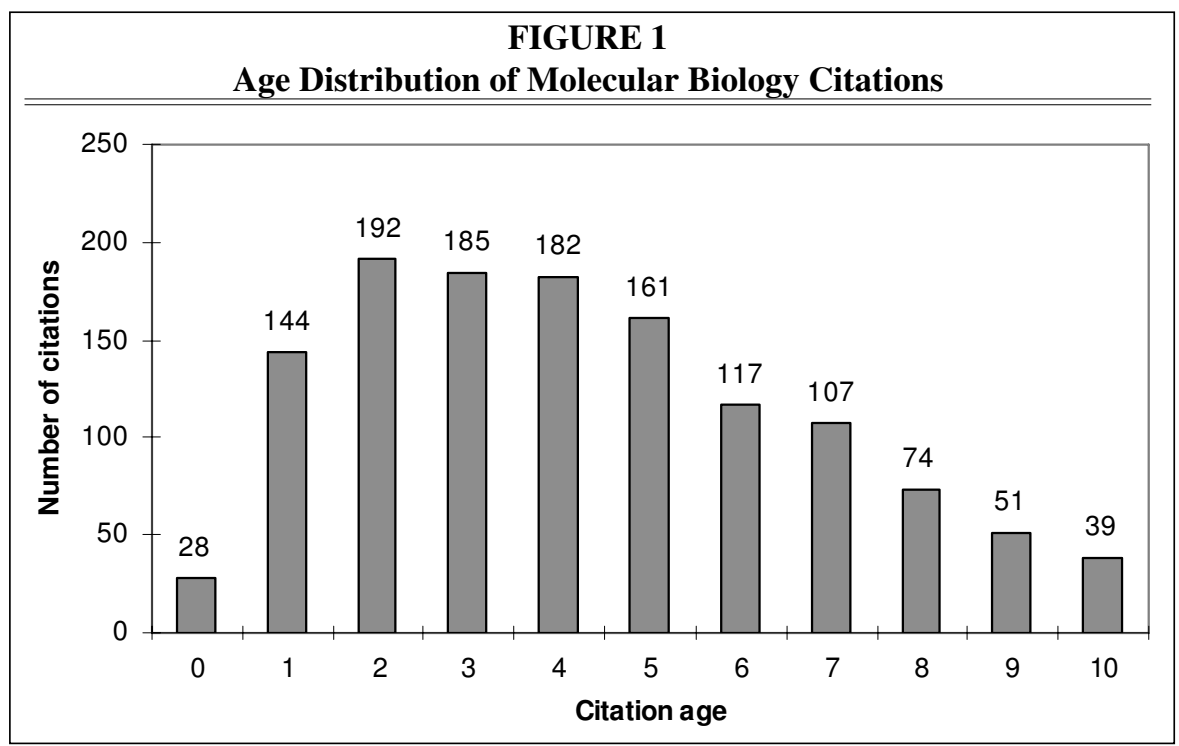

munications to seek and acquire information. An interest in electronic journals is beginning to be apparent as publishers initiate electronic equivalents of paper publications and promote these directly to scientists. These developments have a number of implications for information services and reference departments.

The traditional model of reference units in libraries consists of a highly visible service point staffed by knowledgeable librarians located in the midst of a reference collection. Library users may ask questions there about finding information on a subject or locating items for which they hold citations. If they seek information on a topic, patrons would typically be directed to an appropriate secondary service and offered guidance on using it, if they were unfamiliar with the source. In the 1970s, print indexes and abstracts became available as online databases, and public services staff learned to become skilled mediators and searchers of electronic resources. In the 1980s, databases also appeared as CD ROM products with user-friendly interfaces accessible from workstations within the library, and possibly across a local area network, and librarians became trainers assisting end users in carrying out their own literature searches. At the same time, many large research libraries elected to acquire databases and mount them locally on an institutional computer searchable across a campus network. This marked a significant change in service delivery in that resources once housed in the library were now accessible from offices, laboratories, and sometimes homes. Libraries responded by providing network-accessible documentation for their electronic resources, developed network-deliverable training modules, and established communication channels between the library and its users based on electronic mail and the World Wide Web.

The UIC Library has attempted to develop its services to take full advantage of electronic resources that librarians have promoted enthusiastically. Library services and resources are featured on the library's Web page that offers links to local and remote resources. Subject-based Web pages, including one for molecular biology, are available to guide users to databases, electronic full-text resources, and more. The library is positioned as an advocate of technological innovation in the delivery of information; librarians have assumed the role of change agents in their interactions with library users. Sociologist Everett M. Rogers has studied the diffusion of innovation, and his writings 
offer insights into factors that affect the rate of adoption of innovations. ${ }^{13}$ Variables that Rogers identified include perceived attributes of the innovations such as relative advantage, compatibility, complexity, trialability, and observability, as well as features of the adopting group including its norms and degree of interconnectedness. Thorough understanding of these factors by librarian/ change agents can inform promotion efforts and design of training programs. ${ }^{14}$

\section{The authors hypothesize that molecular biologists will increas- ingly use and cite a variety of electronic resources in their future publications.}

This particular study of the citations in publications of a group of molecular biologists represents a snapshot of their use of resources at the beginning of a period of change. Although secondary services important to their specialization had been available for some years in electronic format, only a very few electronic journals had begun publication when the study sample was drawn. Similarly, the genome databases were emerging and deposition of sequencing data was only a recent requirement for publication of research articles. The authors hypothesize that molecular biologists will increasingly use and cite a variety of electronic resources in their future publications. As information specialists, the authors have opportunities to work with scientists during the coming transition; the authors' understanding of the organization of information and their early involvement in use and development of electronic information sources provide them with an expertise that can be shared.

Molecular biologists have a variety of disciplinary backgrounds and may be based in more than one academic department within the university environment. Their information needs and use patterns reflect this diversity, which is further influenced by their individual research specializations and funding sources. A decen- tralized library system offers challenges to interdisciplinary researchers; in the case of molecular biologists, materials needed may be located in both a medical library and a science library on a given campus. Furthermore, it is likely that no single indexing and abstracting service covers all the publications of interest to them. The citation patterns of the molecular biologists the authors studied suggest that BIOSIS and MEDLINE/Index Medicus are likely to be most useful to them, but that Biotechnology Abstracts and $\mathrm{CAB}$ Abstracts also could be valuable in some specializations. The sixteen most-cited journals listed in table 4 are all covered by MEDLINE and BIOSIS; searching only one of these files would serve to retrieve references from journals most used by molecular biologists. Differences in coverage of the two services will be significant only for coverage of less frequently cited titles, and likely only in some specializations. This is an area where additional research might prove useful.

All the services mentioned above are published in both paper and electronic formats, and for more than two decades, research libraries have provided mediated searching of the databases. Recently, with the advent of user-friendly CD-ROM and network-accessible versions of these databases, many libraries have experienced a decline in mediated searching, presumably because of a corresponding increase in end-user searching either in the library or externally. Proactive librarians have stepped in to fill a need for instruction and training in searching; the rapid growth of the Internet and Web-based resources has added to these opportunities.

Genome databases are one example of a new type of format for resources in molecular biology. GenBank (National Center for Biotechnology Information), DDBJ (DNA Databank of Japan), and EMBL (European Molecular Biology Laboratory) are the largest of the sequence databases; all will likely be of increasing importance to molecular biologists. Such 
resources are not held by a library as traditional print format tables and handbooks are but, rather, typically are accessed over the Internet using Web browsers. Specialized software, also available via the Web, allows scientists to manipulate genetic data and protein sequences and to visualize the three-dimensional structure of DNA, proteins, and smaller molecules. Thus, the genome databases are more than passive sources of sequencing data; they allow interactive use and synthesis of the information they contain to support additional discoveries.

The increasing number of electronic journals that are available over the Web (e.g., Journal of Molecular Biology Online) also have the potential to impact information services. Libraries need to provide not just the compatible browsers that allow viewing text and images, but also "helper applications," such as Acrobat Reader, that will allow viewing, downloading, and printing of documents in PDF formats.

\section{Implicatlons for Collection Development and Management}

The molecular biologists whose citation practices formed the basis for this study use both basic sciences and medical information sources, and might need to visit more than one library to obtain all the journals required to support a research project. The citation data show that the journals used most frequently by molecular biologists are basic science journals rather than medical titles, as classified by Ulrich's. At the time of this writing, many of the titles were held in both LHS and the Science Library. Table 4 lists the journals cited most frequently by molecular biologists: nineteen $(65.52 \%)$ of the titles are held in both libraries, whereas seven $(24.14 \%)$ are at LHS only and three $(10.34 \%)$ are only at the Science Library. The eleven most-used titles are held at both libraries, and currently 89.66 percent of the top-cited journals are available on the same side of campus as the MBRB. This indicates that at the present time most of the needed literature is conve- niently available. When looking at the source journals in table 1 , a high percentage, 92.59 percent, are also available at LHS to meet the needs of MBRB faculty. It appears that both the journals in which these scientists publish and the journals they cite most frequently are currently located in the library site closest to their laboratory.

Issues of access appear to differ if the information use patterns of specific departments are considered. The Department of Genetics, part of the College of Medicine, is located on the west side of campus. Most of the faculty conduct research in the MBRB. Of the journals most cited by MBRB Genetics faculty, 80.95 percent are available at LHS, whereas only 14.29 percent are available only at the Science Library. The Department of Biological Sciences is located on the east side of campus, but many of the faculty have research laboratories on the west side of campus in the MBRB. Of the journals cited by the MBRB biological sciences faculty, 60 percent of the titles are available on both sides of campus, whereas 40 percent are available only at the Science Library on the east side of campus. Much of the literature needed by MBRB biological sciences faculty is therefore not on the same side of campus as their research laboratories.

The results of this study argue for the maintenance of two subscriptions to high-use titles to meet the needs of faculty and students on both sides of campus. Many basic sciences titles are used by departments and researchers on the west side of campus who do not have easy access to the Science Library. However, in past years, materials budget increases have not kept pace with journal price inflation, and the university library has canceled journals to remain within budget, as have most academic libraries in the United States. One targeted group of titles has always been the basic sciences duplicates between LHS and the Science Library. In 1996 alone, forty-nine titles were canceled at LHS that were duplicates of those held by the Science Library in or- 
der to preserve some of the unique titles at LHS and still remain within budget. Several years previously, a much larger number of duplicates between LHS and science were canceled at LHS.

One strategy for coping with the needed cancellations has been to initiate an exchange program between LHS and science in which the current issues of certain titles are sent to the other library for one week so that faculty and students may scan the literature published in these titles. However, as more titles are canceled, there is growing concern that the exchange list is becoming too large, especially the number of titles going from science to LHS. Alternate methods of coping with the cancellation of duplicate copies need to be explored, especially as it is anticipated that future years will bring the cancellation of more duplicate subscriptions. This will be especially vital for the researchers of the MBRB who rely on literature from both libraries.

Another approach might be to subscribe to electronic versions of high-use journals as a second copy. In this scenario, not only will the titles be available on both sides of campus, but they will be available at the desktop within the MBRB, an ideal situation. Of the top ten journals most cited by molecular biologists, five were available electronically at the time of this writing, three directly from the publisher, and two from a third-party provider. However, most of the electronic journal subscriptions also required an additional payment, sometimes more costly than the print subscription in the case of the two titles available from a third-party provider. Therefore, electronic journals will need to be evaluated on a case-bycase basis as a means of offering greater access to faculty on both sides of campus while saving money.

If electronic journals are determined to be too costly, current awareness needs might be met by distributing tables of contents of most-cited journals electronically, as either part of a Web page or as a file distributed periodically to any interested subscribers. For a number of years, the library has subscribed to the Current Contents electronic databases and has produced other similar customized services from the databases.

If escalating costs prevent the acquisition of electronic journals to meet the needs of MBRB faculty, another option would be expanding an intracampus document delivery system between the

\section{Of the top ten journals most cited by molecular biologists, five are currently available electronically, three directly from the publisher, and two from a third-party provider.}

Science Library and LHS. Currently, such a service is provided at a cost, but use of the service has been modest. As more cancellations become necessary, demand may increase. The best strategy for the future will probably combine all the approaches considered. Future collection development strategies in molecular biology, as well as in other interdisciplinary fields, will likely involve a combination of limited print duplication, print/electronic duplicate subscriptions, table of contents services, and intracampus exchange and delivery.

\section{Directions for Future Research}

This analysis of materials cited by molecular biologists depicts their almost total reliance on the refereed scientific journal, supplemented with sources for methodologies published in handbooks and laboratory manuals. At the time the sample for analysis was drawn, some authors had begun to deposit their sequencing data in genetic databanks. The articles they published represented collaborative projects, and the authors' affiliations documented cooperation that cut across departmental and institutional boundaries. Since these data were collected and analyzed, electronic resources have grown significantly as have opportunities to establish new collaborative relationships. A follow-up study might seek answers to questions such as: 
- Are molecular biologists citing electronic journals?

- Are sequencing data routinely being deposited in GenBank or other, similar databanks?

- Are basic science journals of continuing importance to these scientists?

- Is there evidence of new collabora- tions in coauthored research projects?

- Are new specializations emerging among these molecular biologists?

This study offers a methodological approach that might be employed in seeking answers to such questions, as well as insights into other aspects of information use by molecular biologists.

\section{Notes}

1. Katherine W. McCain, “Core Journal Networks and Cocitation Maps: New Bibliometric Tools for Serials Research and Management," Library Quarterly 61, no.3 (July 1991): 311-36.

2. Katherine W. McCain and James E. Bobick, "Patterns of Journal Use in a Departmental Library," Journal of the American Society for Information Science 32 (July 1981): 256-61.

3. Rosalind Walcott, "Local Citation Studies: A Shortcut to Local Knowledge," Science $\mathcal{E}$ Technology Libraries 14, no. 3 (spring 1994): 1-14.

4. Janet Hughes, "Use of Faculty Publication Lists and ISI Citation Data to Identify a Core List of Journals with Local Importance," Library Acquisitions: Practice \& Theory 19, no. 4 (1995): 403-13.

5. Katherine W. McCain, "Mandating Sharing: Journal Policies in the Natural Sciences," Science Communication 16, no. 4 (June 1995): 403-31.

6. Ann C. Weller, "The Human Genome Project," in Susan Y. Crawford, Julie M. Hurd, and Ann C. Weller, From Print to Electronic: The Transformation of Scientific Communication, ASIS Monograph Series (Medford, N.J.: Information Today, 1996).

7. Robin B. Devin, "Who's Using What?" Library Acquisitions: Practice \& Theory 13, no. 2 (1989): 167-70.

8. Walcott "Local Citation Studies," 5.

9. Hughes, "Use of Faculty Publication Lists and ISI Citation Data," 408.

10. Walcott, "Local Citation Studies," 9.

11. Ibid., 13.

12. Karen L. Curtis, Ann.C. Weller, and Julie M. Hurd, "Information Seeking Behavior: A Survey of Health Sciences Faculty Use of Indexes and Databases," Bulletin of the Medical/Library Association, 81, no. 4 (Oct. 1993): 383-92, _—, "Information Seeking Behavior of Health Sciences Faculty: The Impact of New Information Technologies," Bulletin of the Medical Library Association 85, no. 4 (Oct. 1997): 402-10; —_, "Information Seeking Behavior of Faculty: Use of Indexes and Abstracts by Scientists and Engineers," in Proceedings of the 55th Annual Meeting of the American Society for Information Science (Medford, NJ: Learned Information, Inc., 1992), 136-43; — , "Information Seeking Behavior of Science and Engineering Faculty: The Impact of New Information Technologies," in Proceedings of the American Society for Information Science Mid-Year Meeting (Medford, NJ: Learned Information Today, Inc., 1996), 188-96.

13. Everett M. Rogers, Diffusion of Innovations, 4th ed. (New York: The Free Pr., 1995).

14. Julie M. Hurd and Ann C. Weller, "From Print to Electronic: The Adoption of Information Technology by Academic Chemists," Science \& Technology Libraries 16, no. 3/4 (1997): 147-70. 